University of Nebraska - Lincoln

DigitalCommons@University of Nebraska - Lincoln

\title{
Identification of tetragonal and cubic structures of zirconia using synchrotron $\mathrm{x}$-radiation source
}

\author{
Ram Srinivasan \\ University of Kentucky \\ Robert J. De Angelis \\ University of Nebraska-Lincoln \\ Gene Ice \\ Oak Ridge National Laboratory \\ Burtron H. Davis \\ University of Kentucky
}

Follow this and additional works at: https://digitalcommons.unl.edu/mechengfacpub

Part of the Mechanical Engineering Commons

Srinivasan, Ram; De Angelis, Robert J.; Ice, Gene; and Davis, Burtron H., "Identification of tetragonal and cubic structures of zirconia using synchrotron x-radiation source" (1991). Mechanical \& Materials Engineering Faculty Publications. 27.

https://digitalcommons.unl.edu/mechengfacpub/27

This Article is brought to you for free and open access by the Mechanical \& Materials Engineering, Department of at DigitalCommons@University of Nebraska - Lincoln. It has been accepted for inclusion in Mechanical \& Materials Engineering Faculty Publications by an authorized administrator of DigitalCommons@University of Nebraska Lincoln. 


\title{
Identification of tetragonal and cubic structures of zirconia using synchrotron $\mathrm{x}$-radiation source
}

\author{
Ram Srinivasan \\ Center for Applied Energy Research, University of Kentucky, 3572 Iron Works Pike, Lexington, \\ Kentucky $40511-8433$
}

Robert J. De Angelis

Department of Mechanical Engineering, 255 Walter Scott Engineering Center, University of Nebraska at Lincoln, Lincoln, Nebraska 68688-0525

Gene Ice

Oak Ridge National Laboratory, Oak Ridge, Tennessee 37831

\author{
Burtron H. Davis \\ Center for Applied Energy Research, University of Kentucky, 3572 Iron Works Pike, Lexington, \\ Kentucky $40511-8433$
}

(Received 16 February 1990; accepted 6 February 1991)

X-ray diffraction from a synchrotron source was employed in an attempt to identify the crystal structures in zirconia ceramics produced by the sol-gel method. The particles of chemically precipitated zirconia, after calcination below $600{ }^{\circ} \mathrm{C}$, are very fine, and have a diffracting particle size in the range of 7-15 nm. As the tetragonal and cubic structures of zirconia have similar lattice parameters, it is difficult to distinguish between the two. The tetragonal structure can be identified only by the characteristic splittings of the Bragg profiles from the " $\mathrm{c}$ " index planes. However, these split Bragg peaks from the tetragonal phase in zirconia overlap with one another due to particle size broadening. In order to distinguish between the tetragonal and cubic structures of zirconia, three samples were studied using synchrotron radiation source. The results indicated that a sample containing 13 mol \% yttria-stabilized zirconia possessed the cubic structure with $a_{0}=0.51420 \pm 0.00012 \mathrm{~nm}$. A sample containing $6.5 \mathrm{~mol} \%$ yttria stabilized zirconia was found to consist of a cubic phase with $a_{0}=0.51430 \pm 0.00008 \mathrm{~nm}$. Finally, a sample which was precipitated from a $\mathrm{pH} 13.5$ solution was observed to have the tetragonal structure with $a_{0}=0.51441 \pm 0.00085 \mathrm{~nm}$ and $c_{0}=0.51902 \pm 0.00086$.

\section{INTRODUCTION}

Zirconia is a polymorphic ceramic material which may exist in three well-known structural forms: monoclinic, tetragonal, and cubic. ${ }^{1-6}$ Recently, a high-pressure allotropic form of zirconia (orthorhombic) has been reported; this phase is metastable at atmospheric pressure and reverts to the monoclinic form by such a mild treatment as grinding in a mortar. ${ }^{7}$ Although a tremendous amount of research has been carried out to elucidate the crystal structures of industrially important zirconia ceramics, problems remain in assigning the structures accurately. Garvie et al. ${ }^{8}$ reported a cubic dispersion in the tetragonal structure; this appears to have been the only observation of this material. Mazdiyasni et al. ${ }^{9}$ reported that a cubic phase could be obtained by the addition of $6.5 \mathrm{~mol} \%$ yttria, following an alkoxide preparation route.

Davis ${ }^{10}$ found that the $\mathrm{pH}$ at which the precursor gels are precipitated causes the tetragonal or the monoclinic phase to be formed after calcining the material at $400-600^{\circ} \mathrm{C}$. It was reported that the tetragonal phase could be obtained either at a low $\mathrm{pH}(3-5)$ range or at a high $\mathrm{pH}$ range (13-14), and that the monoclinic phase could be obtained in the medium $\mathrm{pH}(8-11)$ range. Srinivasan et al. ${ }^{11}$ demonstrated that the tetragonal phase obtained at $\mathrm{pH} 13.5$ was stable even after calcination at $500{ }^{\circ} \mathrm{C}$ for $300 \mathrm{~h}$ and later found that both the monoclinic and tetragonal phases could be obtained at a $\mathrm{pH}$ of 10.5 , depending upon the time taken to effect the precipitation. ${ }^{12}$ Most recently, Jada and Peletis ${ }^{13}$ suggested that the solution chemistry of zirconia precursor materials plays a key role in controlling the formation of the crystal structure, polymorphic transformation, and crystalline growth. Mamott et al., ${ }^{14}$ using a timeresolved dynamic high-temperature XRPD (X-ray Powder Diffraction) technique, have reported on the onset of an ordering within the amorphous starting material, and on the progress of its conversion into crystalline zirconia.

The assignment of cubic and tetragonal structures, based solely on the x-ray diffraction analysis, can be misleading because the cubic and tetragonal structures 
( $a_{0}=0.5124 \mathrm{~nm}$ for cubic, and $a_{0}=0.5094 \mathrm{~nm}$ and $c_{0}=0.5177 \mathrm{~nm}$ for tetragonal structures) are very similar. ${ }^{15}$ Srivastava et al. ${ }^{16}$ reported that the tetragonal structure can be distinguished from the cubic structure by the presence of the characteristic splittings of the tetragonal phase, such as (002) (200), (113) (311), (004) (400), and (006) (600) etc., whereas the cubic phase exhibits only single peaks at all of these positions. Garvie et al. ${ }^{8}$ utilized high-angle reflections to distinguish the cubic and tetragonal structures and to determine their relative proportions. In an investigation of plasma-sprayed yttriastabilized zirconia coatings, Miller et al. ${ }^{17,18}$ used the (400) region of the $x$-ray diffraction patterns in order to calculate the relative proportions of cubic and tetragonal phases. They reported that the dominant peaks in this region change from the monoclinic to tetragonal and gradually to the cubic reflections with an increase in the level of yttria. A "curve resolver" was used to separate the tetragonal and cubic peak components in the (400) region ${ }^{18}$ and the $d$ values for the (400) and (004) tetragonal peaks were calculated from the curve-resolved peak positions.

It should also be noted that in order to observe clearly the tetragonal splittings in the entire $2 \theta$ region in yttria-containing zirconia ceramics, the material must be sintered above $1100^{\circ} \mathrm{C}$. Below $1100^{\circ} \mathrm{C}$, the $2 \theta$ angle at which tetragonal reflections occur becomes a function of a number of parameters, such as the change in composition, different thermal treatments, variation of the lattice parameters with change in composition, etc. Hannink ${ }^{19}$ has commented that the $(400)_{c}$ profile could not be resolved from the $(400)_{t}$ and $(004)_{t}$ reflections in diffractometer traces such that relative amounts of each phase could be determined. Paterson and Stevens ${ }^{20}$ reported the presence of the $t^{\prime}$ phase, that is strongly related to the cubic phase, and this $t^{\prime}$ phase was observed in the $2 \theta$ region $72-76^{\circ}$.

As these aforementioned works suggest, the $2 \theta$ region used in the assignment and calculation of tetragonal and cubic phases in $\mathrm{ZrO}_{2}$ is complex; care must be exercised when evaluating these crystalline phases using XRD data alone. For samples prepared by precipitation, the doublets of the tetragonal phase at intermediate $2 \theta$ positions are difficult to distinguish clearly because of the peak broadening due to the small crystallite size. Davis $^{10}$ and Srinivasan et al. ${ }^{11,12}$ have suggested that the crystal structure obtained at low $\mathrm{pH}$ values and high $\mathrm{pH}$ ranges is the tetragonal structure, although the tetragonal doublets are not readily apparent in XRD. To confirm their crystal assignment, Srinivasan et al. ${ }^{11,12}$ utilized Raman spectroscopy. In contrast to XRD, the monoclinic, tetragonal, and cubic zirconia structures can be readily distinguished from one another by Raman spectroscopy. Recently, we assigned a tetragonal structure to a zirconia material precipitated from a solution of
$\mathrm{pH}$ 13.5. This assignment was based upon both XRD and Raman spectral evidence that was in agreement with previously published spectroscopic data for the crystalline phases. However, Benedetti et al. ${ }^{21}$ have recently reassigned a cubic structure to a zirconia sample prepared in a similar manner. In this paper, we report further XRD results obtained using a synchrotron source which support our previous assignment in yet another attempt to further the understanding of the crystal structures in precipitated zirconia ceramic materials.

\section{EXPERIMENTAL METHODS}

The complete listing of the specifications for all zirconia samples used in this study is presented in Table I. The $13 \mathrm{~mol} \%$ yttria-stabilized zirconia labeled as sample A was prepared from yttrium and zirconium nitrates using a coprecipitation technique and dried at $120^{\circ} \mathrm{C}$. Sample B was prepared in a manner similar to Mazdiyasni et al. ${ }^{9}$ and contained $6.5 \mathrm{~mol} \%$ yttria. Both samples A and B were calcined at $1150{ }^{\circ} \mathrm{C}$ for $10 \mathrm{~h}$. Zirconia sample $\mathrm{C}$ was precipitated from a solution of $0.3 \mathrm{M} \mathrm{ZrCl}_{4}$ that was adjusted to $\mathrm{pH} 13.5$ with $\mathrm{KOH}$. The resulting product was washed to a negative test for chloride ion (ca. 10 washings) and then calcined at $500{ }^{\circ} \mathrm{C}$ for $200 h^{11,12}$

Samples D and E were prepared in a manner similar to that reported by Benedetti et al. ${ }^{21}$ Sample D, which corresponds to sample III in Ref. 21, was washed twice while sample E (sample II in Ref. 21) was washed exhaustively. Subsequent atomic absorption analysis demonstrated that sample D contained ca. 3 wt. $\% \mathrm{Na}$ and that sample E contained less than $0.5 \mathrm{wt}$. \% Na.

Much of the XRD data reported here were obtained using a synchrotron radiation source. The experiments for our samples were conducted on the beam line X14 (Oak Ridge National Laboratory) at the National Synchrotron Light Source at Brookhaven National Laboratory, Upton, New York. The experiments were performed at room temperature. Two single crystal monochromators

TABLE I. Descriptions of the specimens.

\begin{tabular}{|c|c|}
\hline Sample ID & Specifications \\
\hline Sample A & $\begin{array}{l}13 \mathrm{~mol} \% \text { yttria-stabilized } \mathrm{ZrO}_{2} \text {-calcined at } 1150^{\circ} \mathrm{C}- \\
10 \mathrm{~h}\end{array}$ \\
\hline Sample B & $\begin{array}{l}7.5 \mathrm{~mol} \% \text { yttria-stabilized } \mathrm{ZrO}_{2} \text { obtained from } \\
\text { Ref. } 9-\text { calcined at } 1150^{\circ} \mathrm{C}-10 \mathrm{~h}\end{array}$ \\
\hline Sample C & $\begin{array}{l}\mathrm{ZrO}_{2} \text { precipitated at } \mathrm{pH} 13.5 \text {-calcined at } 500^{\circ} \mathrm{C} \text { for } \\
200 \mathrm{~h}\end{array}$ \\
\hline Sample D & $\begin{array}{l}\mathrm{ZrO}_{2} \text { precipitated using } 4 \mathrm{M} \mathrm{NaOH} \text { at } \mathrm{pH} 14.0 \text {-gels } \\
\text { were washed two times only-containing about } \\
3 \mathrm{wt} \% \mathrm{Na}\end{array}$ \\
\hline Sample E & $\begin{array}{l}\mathrm{ZrO}_{2} \text { precipitated using } 4 \mathrm{M} \mathrm{NaOH} \text { at } \mathrm{pH} 14.0-\text { gels } \\
\text { thoroughly washed-containing }<0.5 \mathrm{wt} \% \% \mathrm{Na}\end{array}$ \\
\hline
\end{tabular}


were used on the beam path so as to allow only the wavelength of $\mathrm{Cu} \mathrm{K}_{\alpha}$ line. As the intensity of the synchrotron source is too high, the use of two monochromators does not account for much loss of intensity due to absorption. Also, the high intensity of the source enables rapid data acquisition. Diffraction data were collected by step scanning for times of one or two seconds per step and a step width of 0.02 or 0.01 degrees in $2 \theta$.

\section{RESULTS AND DISCUSSION}

Synchrotron radiation is a powerful tool for diffraction studies. The high intensity and collimation of synchrotron radiation allows high resolution studies, both in the small- and high-angle regions, and also very close to Bragg reflections. This is useful in a number of applications, including structure analysis. ${ }^{22}$

A typical $x$-ray pattern collected on the synchrotron beam line from a sample of pure monoclinic ( $>95 \%)$ zirconia is presented in Fig. 1(A). This material was prepared from a batch of zirconyl nitrate hydrate; another batch of zirconyl nitrate hydrate from this same supplier produced a material containing a high percentage of tetragonal zirconia. We have been able to obtain this high percentage of monoclinic form by precipitation at $\mathrm{pH} 10$ only when the initial zirconium species are well dispersed, presumably as a monoatomic zirconium species. In most cases, zirconyl salts appear to be polymeric dispersions and this invariably leads to a high percentage of tetragonal zirconia.

The importance of the starting zirconium salt has been ignored repeatedly by workers in the preparation of crystalline zirconia ceramics by precipitation, and we feel that this is a likely source for the diversity of results that have been reported.

An XRD pattern for the tetragonal form of zirconia is shown in Fig. 1(B). It is obvious that the XRD pattern clearly distinguishes the tetragonal and cubic structures from the monoclinic form. However, the XRD patterns for (111) reflections of the cubic $13 \mathrm{wt}$ \% yttria-stabilized zirconia [Fig. 1(C)] and tetragonal zirconia [Fig. 1(B)] are essentially coincident, and therefore the two cannot be distinguished readily from the XRD patterns. Thus, other means of distinguishing between tetragonal and cubic forms become necessary.

The $2 \theta$ region containing (004) and (400) tetragonal doublets is presented in Fig. 2 for all the three samples. This $2 \theta$ region has been extensively used by researchers in order to distinguish the cubic from the tetragonal structure in zirconia. ${ }^{8,17,21,23}$ For sample A the (400) cubic peak is very sharp with a calculated crystallite size of about $96 \mathrm{~nm}$. For sample B (6 mol \% yttria stabilized zirconia) the profile is very broad and the asymmetry of this profile suggests that this material may consist of a mixture of tetragonal and cubic phases with a crystal-

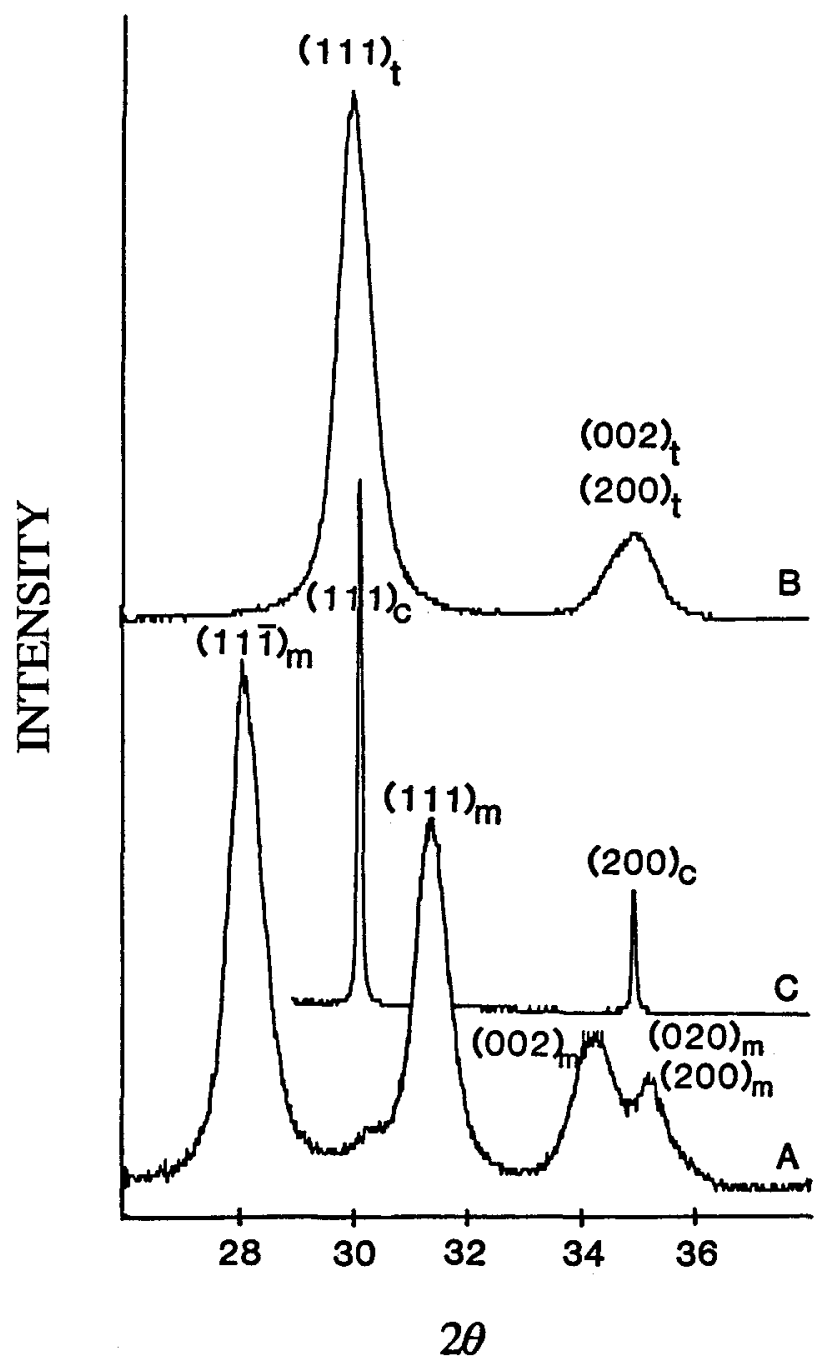

FIG. 1. Typical $x$-ray diffraction patterns using a synchrotron source. (A) $100 \%$ monoclinic zirconia precipitated at $\mathrm{pH} 10.5$ and calcined at $500{ }^{\circ} \mathrm{C}-5 \mathrm{~h}$, (B) $100 \%$ tetragonal zirconia (sample C) and (C) $100 \%$ cubic zirconia (sample A).

lite size estimation of $8.5 \mathrm{~nm}$. However, for sample C the (004) and (400) tetragonal doublets can be observed clearly. It can be observed that the addition of yttria to zirconia has altered the lattice parameters for samples A and $\mathrm{B}$. The high-angle region from $120-134^{\circ}$ is plotted in Fig. 3. Here the (600) cubic peak is observed for sample A; for sample C (006) and (600) tetragonal doublets are observed.

Both the conventional $x$-ray source and synchrotron source were used to obtain patterns from samples $B$ and $\mathrm{C}$ and these contained broad diffraction lines. This indicates the very small crystallite size of the chemically precipitated materials. Despite the broad diffraction lines, a complete XRD pattern was obtained for all the three samples so as to offer a reasonable definition of the crystal structures developed in these materials. Based on the 


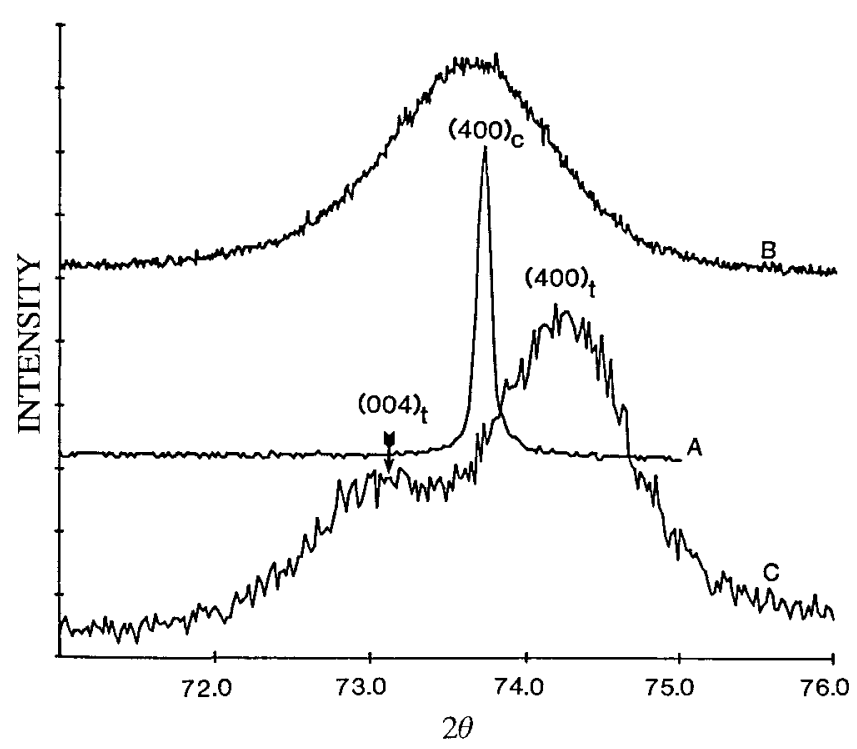

FIG. 2. X-ray diffraction pattern for samples $\mathrm{A}, \mathrm{B}$, and $\mathrm{C}$ in the $2 \theta$ region of $71-76^{\circ}$, where the (400) cubic peak and (004) (400) tetragonal doublets should appear. Curves $(A),(B)$, and $(C)$ refer to samples A, B, and C, respectively.

above XRD results, the crystallite size data were calculated from all the XRD profiles using Scherrer analysis, ${ }^{24}$ and these data are presented in Table II.

The literature for zirconia has inconsistencies, both with regard to structure and to lattice parameters. It is known that the stabilization of zirconia with $13 \mathrm{~mol} \%$ or $6 \mathrm{~mol} \%$ yttria will alter the lattice parameters, and we have considered these two samples only for comparative studies with tetragonal zirconia precipitated at a $\mathrm{pH}$ of 13.5 (sample C). The lattice parameters calculated from the diffraction data using a least-square $\mathrm{fit}^{25}$ indicate that sample A has a cubic structure with $a_{0}=0.51420 \pm$ $0.00012 \mathrm{~nm}$. This conclusion is further substantiated by the Raman spectrum of sample A. ${ }^{26}$ Likewise, sample C is undoubtedly tetragonal zirconia.

We feel that the statement of Benedetti et al. ${ }^{21}$ that the $\mathrm{pH} 13.5$ material, if washed minimally, is cubic $\left(a_{0}=0.5116 \mathrm{~nm}\right)$, is subject to question. The $\mathrm{x}$-ray diffraction patterns using a conventional source from sample D (washed only 2 times) are presented in Fig. 4. Although the $(004)_{t}$ and $(400)_{t}$ phases are not resolved

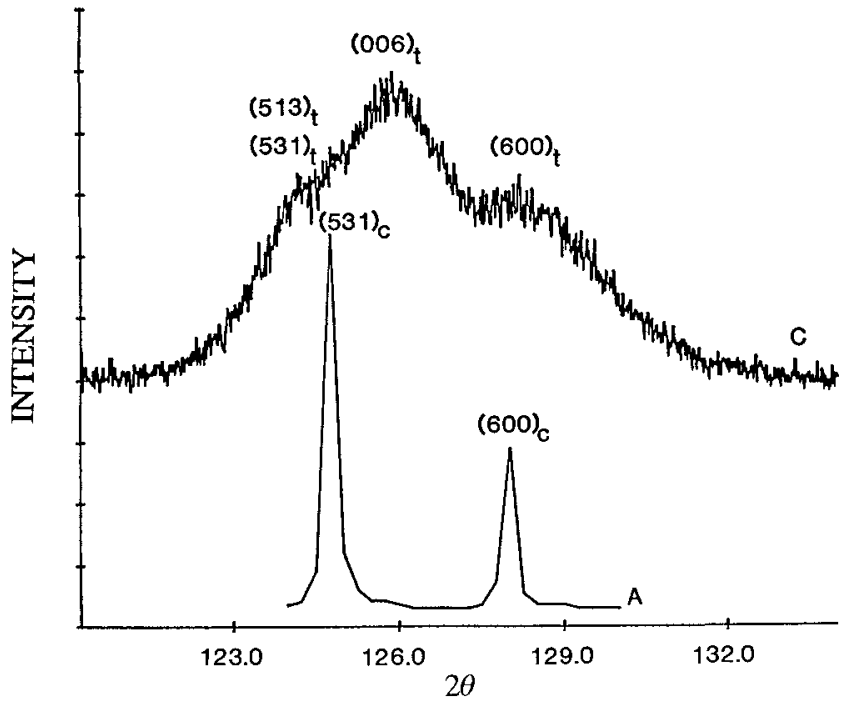

FIG. 3. X-ray diffraction patterns for samples $A$ and $C$ in the $2 \theta$ region of $120-134^{\circ}$. Sample A shows (531) and (600) cubic peaks. Sample $\mathrm{C}$ shows the overlapping (513) and (531) tetragonal doublets. The (006) and (600) tetragonal doublet can be observed clearly without overlap.

well in the $2 \theta$ region of $70-78^{\circ}$ [Fig. 4(A)], the (006) $)_{t}$ and $(600)_{t}$ phases are well resolved in the $2 \theta$ range of $120-132^{\circ}$ [Fig. 4(B)]. Calling this peak 'cubic', based on the inability to observe the (004) $t$ and $(400)_{t}$, will be misleading without checking carefully at the higher angle peaks [i.e., $(006)_{t}$ and $(600)_{t}$ ]. One must therefore exercise extreme caution in assigning a structure to the $\mathrm{pH} 13.5$ material. Usually one cannot assign either the tetragonal or the cubic structure relying solely on the $2 \theta$ range of $70-76^{\circ}$, a region which contains only the $(004)$ and (400) tetragonal doublets and the (400) cubic singlet. As a result of the ambiguity surrounding the true crystal structure of the $\mathrm{pH} 13.5$ material, we have undertaken XRD studies using a synchrotron source. With conventional x-ray diffraction, because of the very small crystallite size, the tetragonal doublets often cannot be clearly resolved. On the other hand, XRD studies utilizing a synchrotron source have the capability of distinguishing further the tetragonal doublets even for a material consisting of very fine crystallites. This is clearly apparent by comparing Figs. 2(C) and 4(A).

TABLE II. Crystallite size data for samples A, B, and C.

\begin{tabular}{lcccccccccccccc}
\hline \hline & \multicolumn{10}{c}{ Crystallite size (nm) } \\
\cline { 2 - 14 } & $(111)$ & $(200)$ & $(002)$ & $(220)$ & $(202)$ & $(311)$ & $(113)$ & $(222)$ & $(400)$ & $(004)$ & $(331)$ & $(420)$ & $(600)$ & $(006)$ \\
\hline Sample A & 106 & 103 & $\ldots$ & 105.5 & $\ldots$ & 102 & $\ldots$ & 91 & 96 & $\ldots$ & 101 & 104 & 95 & $\ldots$ \\
Sample B & 10 & 10.2 & 10.2 & 9.5 & 9.5 & 9.5 & 9.5 & 9 & 8.5 & 8.5 & 9.5 & 9.2 & $\mathrm{a}$ & $\mathrm{a}$ \\
Sample C & 13 & 9 & 9 & 10.3 & 10.3 & 8 & 8 & 11.2 & 10.8 & 8.5 & 9.5 & 7.5 & 5 & 5.2 \\
\hline \hline
\end{tabular}

${ }^{a}$ Not available. 


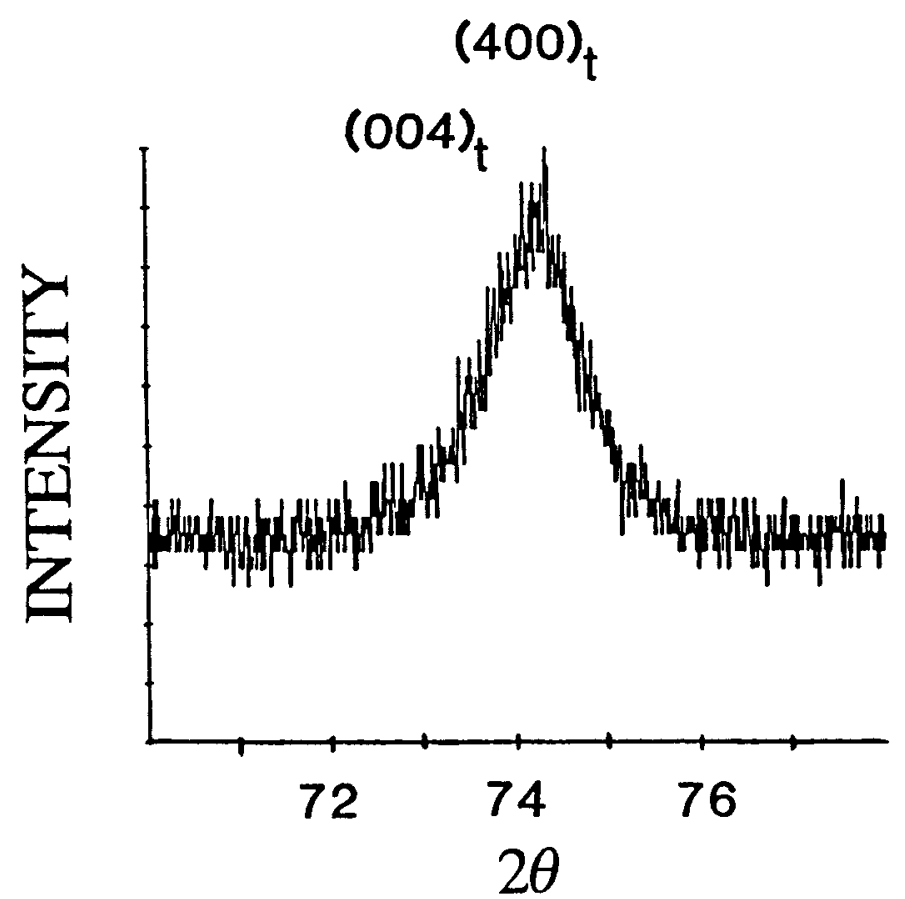

(a) $(006)_{t}$

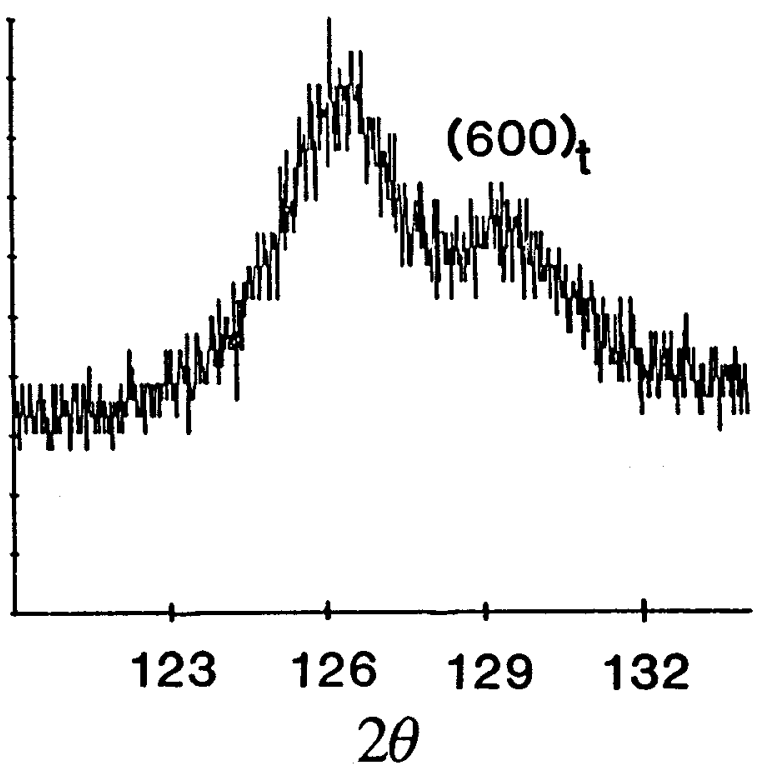

(b)

FIG. 4. X-ray diffraction patterns for sample D. Although the $(004)_{t}$ and $(400)_{t}$ are not well resolved, the $(006)_{t}$ and $(600)_{t}$ profiles can be seen clearly resolved.

The ambiguity in the tetragonal doublets in Fig. 4(A) is correctly resolved in Fig. 2(C). The superiority of a synchrotron source is again apparent by comparing Figs. 3(C) and 4(B), wherein the synchrotron source clearly resolves the overlapping XRD profiles. Hence, one should examine higher order peaks, such as (006) and (600) tetragonal doublets in the $2 \theta$ range of $120-132^{\circ}$, to ascertain accurately the crystal identity. In order to corroborate this conclusion further, we recommend that Raman studies also be undertaken. The Raman spectrum for tetragonal zirconia lends support to our conclusion that the $\mathrm{pH} 13.5$ material is tetragonal. ${ }^{26}$ For zirconia, precipitated employing $\mathrm{NaOH}$ to produce a $\mathrm{pH}$ of 13.5 , the tetragonal form has been obtained whether the washing was limited or extensive. We have not obtained evidence to support the view that $\mathrm{ca} .3 \% \mathrm{Na}$ can stabilize the cubic form of zirconia, as was reported in Ref. 21.

\section{CONCLUSIONS}

X-ray diffraction using a synchrotron source has been adopted to provide a better definition of certain controversial points in the assignment of the crystal structure in zirconia. It is clear that if zirconia is precipitated at a $\mathrm{pH}$ of 13.5, it develops the tetragonal phase and not the cubic form. Both Raman and XRD studies lend support to our conclusions about the structure in the precipitated zirconia. We have found that particle size broadening of
XRD profiles can lead potentially to incorrect structural assignments. It is therefore concluded that a more complete analysis including Raman spectroscopy in addition to XRD should be undertaken before positively assigning the crystal structures to materials of very small crystallite size, a situation in which particle size broadening of XRD data can be overwhelming.

\section{ACKNOWLEDGMENTS}

This work was supported, in part, by the Commonwealth of Kentucky through the University of Kentucky, Center for Applied Energy Research Laboratory, the Department of Energy, Contract No. DE-FG05-85ER 45186 at the University of Kentucky. Help rendered by Mr. Gerald A. Thomas for carrying out atomic absorption experiments is acknowledged with thanks. Travel grants from the Oak Ridge Associated Universities, ORNL, Tennessee, to undertake the trip to the Brookhaven National Laboratory are gratefully acknowledged.

\section{REFERENCES}

1. O. Ruff and F. Z. Ebert, Anorg. U. All. Gem. Chem. 180, 19-41 (1929).

2. P. Murray and E.B. Allison, Trans. Brit. Ceram. Soc. 53 (6), 335-361 (1954).

3. C. T. Lynch, F. W. Bahldiek, and L. B. Robinson, J. Am. Ceram. Soc. 44 (3), 147-148 (1961).

4. R. N. Patil and E. C. Subba Rao, Acta Crystallogr. A26, 555 (1970). 
5. H. S. Maiti, K. V. G. K. Gokhale, and E. C. Subba Rao, J. Am. Ceram. Soc. 55 (6), 317-322 (1972).

6. A. H. Hueur and M. Rühle, in Advances in Ceramics, edited by N. Claussen, M. Rühle, and A.H. Hueur (Am. Ceram. Soc., Columbus, OH, 1984), Vol. 12, pp. 1-13.

7. R. Suyama, T. Ashida, and S. Kume, J. Am. Ceram. Soc. 68 (12), C-134 (1985).

8. R. C. Garvie, R. H. Hannink, and R. T. Pascoe, Nature 258, 703 (1975).

9. K. S. Mazdiyasni, C. T. Lynch, and J. S. Smith, II, J. Am. Ceram. Soc. 50 (10), 532 (1967).

10. B. H. Davis, J. Am. Ceram. Soc. 67 (8), C-168 (1984).

11. R. Srinivasan, R. J. De Angelis, and B.H. Davis, J. Mater. Res. 1, 583 (1986).

12. R. Srinivasan, M. B. Harris, S. F. Simpson, R. J. De Angelis, and B. H. Davis, J. Mater. Res. 3, 787 (1988).

13. S. S. Jada and N.G. Peletis, J. Mater. Sci. Lett. 8, 243-246 (1989).

14. G. T. Mamott, P. Barnes, S. E. Tarling, S. L. Jones, and C. J. Norman, Powder Diffraction 3 (4), 234-239 (1988).

15. Magnesium Elektron Publication \#113, Zirconia and Zirconia Ceramics, edited by R. Stevens (Magnesium Elektron Ltd., 1986).
16. K. K. Srivastava, R. N. Patil, C.B. Choudhary, K. V. G. K. Gokhale, and E. C. Subba Rao, Trans. Brit. Ceram. Soc. 73 (5), 85-91 (1974).

17. R. A. Miller, R.G. Garlick, and J. L. Smialek, J. Am. Ceram. Soc. Bull. 62 (12) (1983).

18. R. A. Miller, J. L. Smialek, and R.G. Garlick, in Adv. Ceram. III. Science and Technology of Zirconia, edited by A. H. Hener and L.W. Hobbs (Am. Ceram. Soc., Columbus, OH, 1981), pp. $241-253$.

19. R. H. J. Hannink, J. Mater. Sci. 13, 2487 (1978).

20. A. Paterson and R. Stevens, J. Mater. Res. 1, 295 (1986).

21. A. Benedetti, G. Fagherazzi, and F. Pinna, J. Am. Ceram. Soc. 72 (3), 467 (1989).

22. J. B. Hastings, W. Thomlinson, and D. E. Cox, J. Appl. Cryst. 17, 85-89 (1984).

23. T. K. Gupta, J. Mater. Sci. 12, 2421-2426 (1977).

24. H.P. Klug and L.E. Alexander, X-Ray Diffraction Procedures (Wiley \& Sons, New York, 1967), p. 491.

25. M. H. Mueller, L. Heaton, and K. T. Miller, Acta Crystallogr. 13, 828 (1960).

26. R. Srinivasan, S.F. Simpson, J. M. Harris, and B.H. Davis, J. Mater. Sci. Lett. (in press). 